\title{
Study on Fitting Dress' Comfort of Vocality Performer Based 3D Technology
}

\author{
Zifei LI*, Huanyun WEI, Li ZHOU \\ College of Textile \& Garment, Southwest University, Chongqing, China
}

DOI: 10.15221/17.071 http://dx.doi.org/10.15221/17.071

\begin{abstract}
From the angle of breathing movement, this paper takes the singer of the female singing as the object of the study, which is both focus on the research of the body breath status of performers before and after wearing tunic dresses and analysis of the relationship between performer's breathing movement and dress comfort. Base on this, the 3DCaMega human body scanning system is used to obtain the point cloud data of the performers in the same state to establish the virtual human body model- and according to-the model data and comfortable level. Clo3D is utilized to optimize the structure of tunic fitting. Finally, Clo3D is used to simulate the fitting and to prove the comfort of the tunic dress, Making sure performers can gain excellent artistic singing effects.
\end{abstract}

Keywords: vocal dress, clothing pressure, structure optimization

The art of vocal singing is a form of music that has created and evolved in the long-term development of mankind. It mainly includes singing, performing and two degree creations. The singers are often influenced by different factors in vocal music performance, including psychological state, breath control, clothing comfort and song difficulty etc. Among them, the costumes which the singers wear in the course of the performance often become the "second voices" of the performers, which make the audience feel the double enjoyment of sight and hearing. So a dress of fit is important to a vocal performance as a performer's voice.

\section{Background of research}

\subsection{The breathing state during vocal performance}

Singing is produced by the movement of the body's vocal system. There are three types of breathing that are commonly used: upper chest breathing, abdominal breathing, and chest abdominal combined breathing. Among them, the chest abdominal combined breathing method is the most scientific, ideal and physiological method which is widely used ${ }^{[1]}$. The movement of the respiratory muscles in the waist and abdomen is the source of the singing breath, while the expansion of the chest is the storage station for the singing breath. The frequency of breathing in normal adults varies with age, sex, and physiological status: adults breathe at a rate of about 10-15 breaths per minute during quiet periods. Their lung capacity is usually $3500 \mathrm{cc}$ for man (CC: the units of volume, equivalent to ML), and 2200cc for women. The breath of a singer in the course of performance is closely relevant to the pitch and rhythm. To name only a few: Wang Qingshuang in singing "Butterfly Lovers new song" B2 paragraph, as the pace of speeding up, 45 seconds of ventilation have reached 18 times.

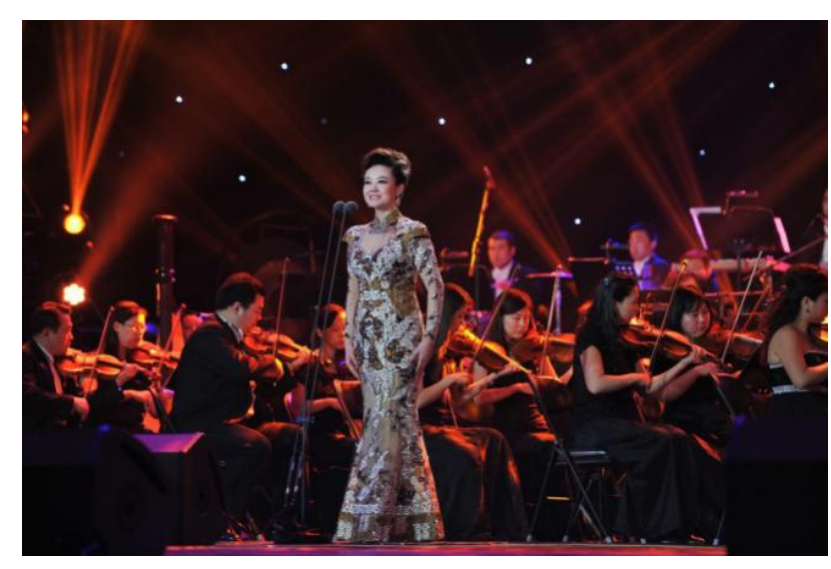

Fig.1. Wang Qingshuang singing

* Fund project: This research is supported by "Fundamental Research Funds for the Central Universities (XDJK2016C100)".

About the Author:LI Zifei , female, postgraduate, the main research direction is the digital clothing design. Communication author: LI Zifei, E-mail: 563191901@qq.com. 


\subsection{Costume in vocal music performance}

Today, the majority of the vocal performances require wear the tunic dress (as shown in figure 2) with an elegant, calm and sedate style features, and show the curves of the female body, lest the audience can enjoy the visual enjoyment of the singer's dress while listening to the song. But the singer is nervous thinking before the show because of psychological and physiological factors, worries about not enough breath, leading to consciously abdomen, at this time wear fit is appropriate. And as the performer transforms the pitch and rhythm of the song during the performance, a phrase one breath has been unable to meet the singing needs, the singer's breathing rate increased to more than 13 times per minute, vibrations resonate more violently, the movement of the chest cavity and the abdominal cavity will be greatly limited to the clothing, and cannot control the breath freely, resulting in a short breath, floating in the chest, the sound sounds empty, no foundation, sound dull, stiff, not thorough, flexible.

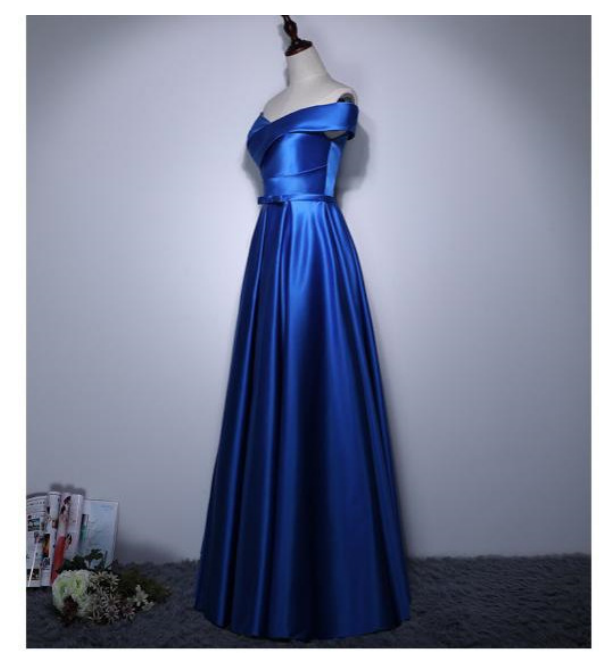

Fig.2. vocal dress

Thus it can be seen that the performance of the singing performance is multifaceted. In terms of songs, the emphasis of singing is natural fluency, attaches importance to the fluidity of the breath rather than rigidity; in terms of the costumes of the performers, human ergonomic requirements should be met. Style should meet the waist, abdomen and chest space required for movement, improve the comfort and fit of clothes, choose more expressive and striking colors, accord with the transform relation of optics and color, the fabric has the certain elasticity and degree of fit and comfort. What is more, from the point of view of experiment, analyze the relation between clothing and breathing movement in vocal music performance.

\section{Process of the research}

\subsection{Pressure comfort test.}

For the human body, the range of pressure of clothing comfortable is $1.96 \sim 3.92 \mathrm{kPa}(\mathrm{KPa}$, a physics term for stress 1000KPA. In an international unit, the unit of pressure is $\mathrm{N} / \mathrm{m} 2$, which read as Newton per square meter) [2]. This experiment takes the singer of the national female singing as the object of studies, when they wearing a tunic dress singing the same song, study their natural singing, put the arms naturally and hold high arms in three different states, pressure measurements were performed at 3 high chests, chests lower, and abdominal areas by using an airbag pressure sensor. The pressure changes in different states of performers are analyzed in real time, the tunic dress in the 3 main parts of the optimal pressure value.

\subsubsection{The requirements of try on personnel}

The subjects of this experiment were 18-24 year old vocal students, 5 college students and graduate students vocal majors, between the $158-165 \mathrm{~cm}$. The sample selection in the fell to the ground waist dress, manually adjustable bra straps style, clothing sizes for $M$, clothing material: polyester fiber $80 \%$, others $20 \%$. The selected track for the experiment is folk song "gan xu gui lai a lili".

\subsubsection{Subjective questionnaire design}

The subjective evaluation questionnaire recorded 5 items of physiological data, related test areas, testing posture, sensory index description and scoring criteria. While measuring comfort, there are other clothes to feel, specific: sense of weight, sense of bondage, oppressive feeling, overall comfort. The stress degree of different test parts is divided into five grades: no pressure, slight pressure, moderate pressure, strong pressure and strong pressure respectively. The corresponding scores were 1,2,3,4 and 5, respectively. 


\subsubsection{Research process}

First of all, select the subjective evaluation of personnel to meet the corresponding requirements, at the same time according to the law of singing, set 3 kinds of the basic state of action: under the vertical arm, arm upright, arms straight upright(as shown in figure.3). Secondly, according to the characteristics of tunic dress and the body trunk recoil induction sensitive point, selected 3 tests points: A (bust Point), B (chest circumference), C (waist and abdomen) (as shown in figure 4). Because the human body is symmetrical, select the right side of the human body to do experiments. In the artificial climate chamber, after each test wearing tunic dress completes an action and according to their own feelings of the pressure of the evaluation point and related feeling to make judgments, according to the feeling of trying to fill out the questionnaire, 3 actions were completed in succession completed the questionnaire.
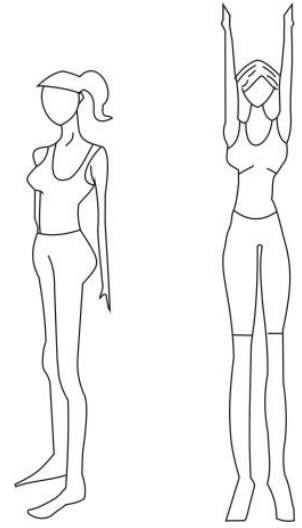

Fig.3. Measuring posture

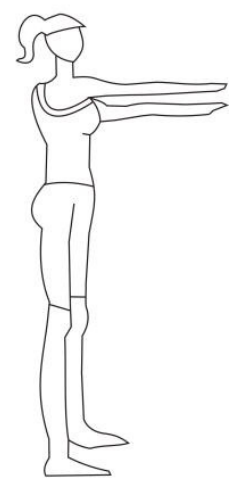

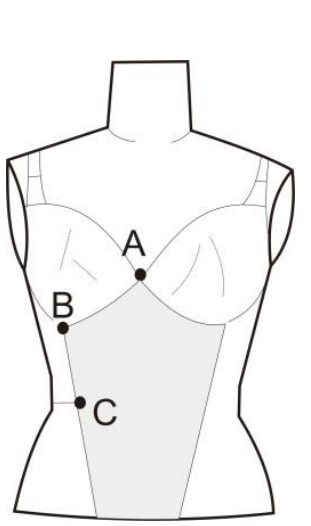

Fig .4. Test point

\subsection{Experimental result analysis}

2.2.1. Total sensory characteristics analysis

Table 1.Descriptive statistics analysis

\begin{tabular}{ccccccc}
\hline & No.1 tester & No.2 tester & No.3 tester & No.4 tester & No.5 tester & $\begin{array}{c}\text { average } \\
\text { value }\end{array}$ \\
\hline $\begin{array}{c}\text { Weight } \\
\text { sense }\end{array}$ & 2.13 & 2.21 & 2.09 & 2.25 & 2.16 & 2.16 \\
\hline $\begin{array}{c}\text { bondage } \\
\text { sense }\end{array}$ & 3.03 & 2.98 & 3.05 & 3.12 & 3.01 & 3.05 \\
$\begin{array}{c}\text { Oppressive } \\
\text { feeling }\end{array}$ & 3.27 & 3.19 & 3.28 & 3.12 & 3.26 & 3.22 \\
$\begin{array}{c}\text { overall } \\
\text { comfort }\end{array}$ & 2.23 & 2.19 & 2.06 & 2.33 & 2.17 & 2.20 \\
\hline
\end{tabular}

In the mean comparison, the score of dress weight (2.16) before singing is between "slight" and "proper"; the score of bondage sense (3.05) is between "proper" and "strong"; The score of oppression (3.22) is between "proper" and "strong", and the overall comfort (2.20) is between "slight" and "appropriate".

\subsection{2 .Pressure characteristic analysis}

Table.2. Pressure values at each point before singing (unit: $\mathrm{kPa}$ )

\begin{tabular}{ccccccc}
\hline & No.1 tester & No.2 tester & No.3 tester & No.4 tester & No.5 tester & $\begin{array}{c}\text { average } \\
\text { value }\end{array}$ \\
\hline point A & 2.16 & 2.21 & 1.96 & 2.28 & 2.08 & 2.14 \\
point B & 3.11 & 3.02 & 3.13 & 3.21 & 3.05 & 3.10 \\
point C & 3.55 & 3.48 & 3.36 & 3.52 & 3.42 & 3.46 \\
\hline
\end{tabular}


As you can see from the table above, before singing the mean pressure of A point (2.14) is between "minor" to "appropriate"; the mean pressure point B (3.10) in the "appropriate" to "strong"; pressure mean C points (3.46) in the "strong" to "strong".

Table.3. The pressure at each point of vertical singing under the arm (unit: $k P a)$

\begin{tabular}{ccccccc}
\hline & No.1 tester & No.2 tester & No.3 tester & No.4 tester & No.5 tester & $\begin{array}{c}\text { average } \\
\text { value }\end{array}$ \\
\hline point A & 2.53 & 2.56 & 2.42 & 2.92 & 2.60. & 2.60 \\
point B & 3.06 & 3.12 & 3.08 & 3.22 & 3.13 & 3.12 \\
point C & 3.33 & 3.42 & 3.50 & 3.46 & 3.39 & 3.42 \\
\hline
\end{tabular}

As you can see from the table above, when tester sing with up-right and arm droop the mean pressure of $A$ point $(2.60)$ is between "minor" to "appropriate"; the mean pressure point B (3.12) in the "appropriate" to "strong"; pressure mean C points (3.42) in the "strong" to "strong".

Table.4. The pressure at each point of vertical singing upright arm (unit: $\mathrm{kPa}$ )

\begin{tabular}{lcccccc}
\hline & $\begin{array}{c}\text { No.1 } \\
\text { tester }\end{array}$ & $\begin{array}{c}\text { No.2 } \\
\text { tester }\end{array}$ & $\begin{array}{c}\text { No.3 } \\
\text { tester }\end{array}$ & $\begin{array}{c}\text { No.4 } \\
\text { tester }\end{array}$ & $\begin{array}{c}\text { No.5 } \\
\text { tester }\end{array}$ & average value \\
\hline point A & 2.98 & 2.76 & 2.88 & 3.02 & 3.06 & 2.94 \\
point B & 3.13 & 3.08 & 3.15 & 3.09 & 3.16 & 3.12 \\
point C & 3.21 & 3.19 & 3.25 & 3.33 & 3.34 & 3.26 \\
\hline
\end{tabular}

As you can see from the table above, when tester sing with up-right with your arms erect the pressure values at three, B, C, and A are all between "proper" and "stronger".

Table .5. The pressure at each point of vertical singing $(\mathrm{kPa})$

\begin{tabular}{ccccccc}
\hline & $\begin{array}{c}\text { No.1 } \\
\text { tester }\end{array}$ & $\begin{array}{c}\text { No.2 } \\
\text { tester }\end{array}$ & $\begin{array}{c}\text { No.3 } \\
\text { tester }\end{array}$ & $\begin{array}{c}\text { No.4 } \\
\text { tester }\end{array}$ & $\begin{array}{c}\text { No.5 } \\
\text { tester }\end{array}$ & average value \\
\hline point A & 2.76 & 2.92 & 2.89 & 2.79 & 3.05 & 2.89 \\
point B & 3.11 & 3.06 & 3.15 & 3.21 & 3.07 & 3.12 \\
point C & 3.36 & 3.28 & 3.35 & 3.16 & 3.31 & 3.29 \\
\hline
\end{tabular}

As you can see from the table above, when tester sing with up-right and arms straight upright the pressure values at three, B, C, and A are all between "proper" and "stronger".

\subsubsection{Result analysis}

The pressure values of each point under different postures are tested we found that: (1) in the tightening degree under the same pressure, A point pressure value increases with the arm lift; B point pressure value has changed with the numerical arm position changes, but little change; $C$ point pressure value gradually decreased with the change of position of the arm;(2) when pressure increases, breathing increases dramatically, and the time at which it begins varies from person to person. From the amplitude of respiration (i.e. the depth of respiration), it was found that the amplitude decreased and the frequency increased, lead to physical uncomfortable in the course of the singing process.

Clothing pressure added to the soft part of the body allows for a $3.928 \mathrm{kPa}$ of hygiene, excess this value may be a barrier to health [3]. In the experiment, although the chest was not directly compressed, respiratory movements were suppressed and had adverse effects on gas metabolism. In addition, tunic dress direct oppression abdomen can lead to digestive function decline, resulting in insufficient blood supply. As a result, a fitted vocal performance dress can not only add to the performer's appearance, but also have a direct impact on the performer's vocal performance and physical fitness.

\subsection{Optimized dress model}

\subsubsection{Build virtual human model}

With the development of $3 \mathrm{D}$ virtual reality technology, numerical clothing pressure is widely used in the evaluation of clothing comfort. The research shows that the simulation of clothing pressure distribution is of vital importance to the optimization design of clothing products. 
On this basis, the 3DCaMega 3D human body scanning system is used to obtain the point cloud data of the performers in the same state, and a human body model of invented is established. The performer stands in the middle of the scanning device. The device scans the human body automatically in 4 different directions, and then collects the whole body image in seconds. Through the conversion of the computer to obtain the human three-dimensional point cloud data map, after getting the optimized point cloud data, we use Geomagic Studio software to transform it into point cloud model, and repair and denoise it, the 3D virtual human body model (Figure 5,6) is generated using optimized cloud data and body data are measured.

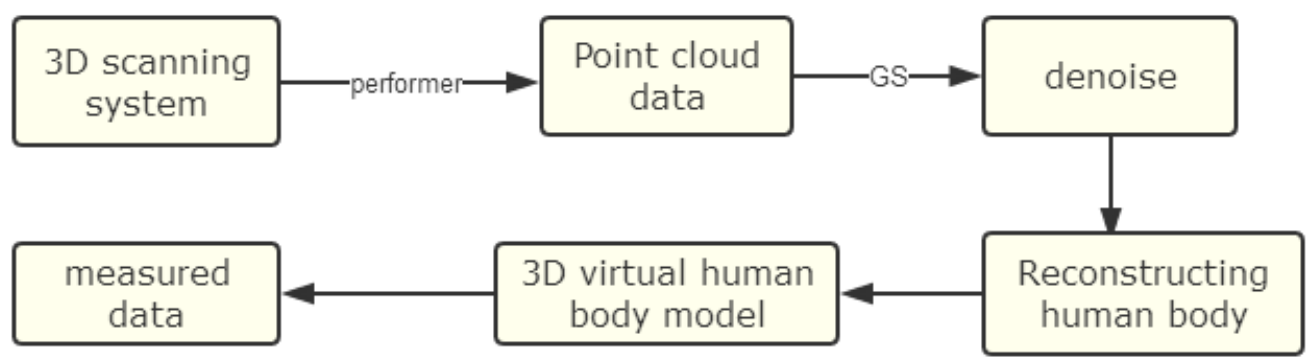

Fig. 5. The flow of establishes of $3 D$ virtual human model

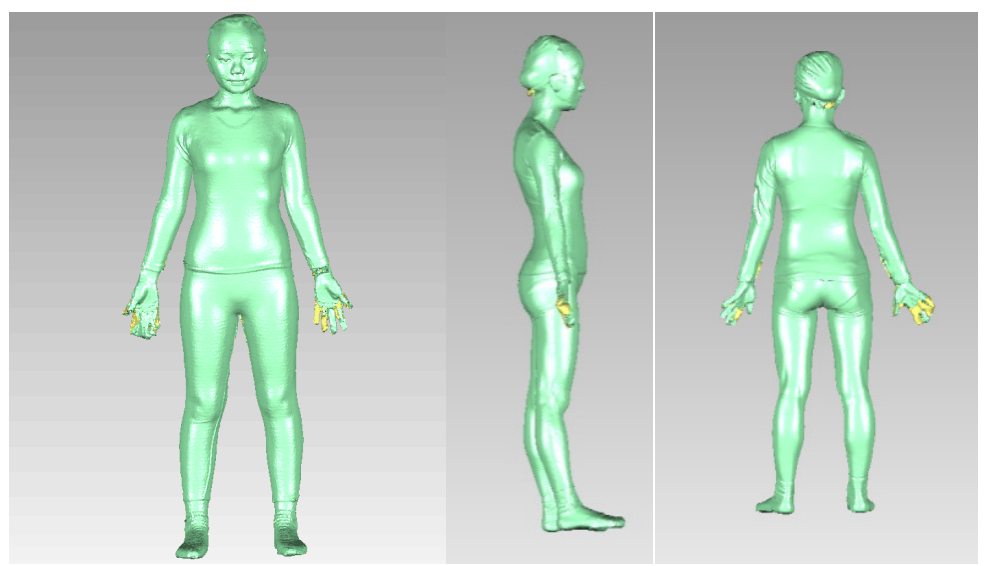

Fig .6.3D virtual human model

\subsubsection{CLO3D body fitting}

Based on human body data obtained based on 3D scan, choose the right color, hair style, and shoes model in the model library, and according to the data obtained from scanning the human body to set the height, shoulder width, chest circumference, waist circumference, arm circumference, etc. The design of dress size requires completing the modeling work of mannequins. In the 3D model on the basis of clothing style, shape design, we need to draw a two-dimensional model of clothing with CAD first, after that import the 2D model into CLO 3D software and make virtual sewing onto the mannequin to form a 3D garment, which is equivalent to wearing the clothes on the human body in real life. The virtual human body is added to the action, and the dynamic effect of the dress after stitching can be observed directly. And according to the effect of fitting of the human body, adjust the 2D clothing model, and the virtual window can be modified synchronously.

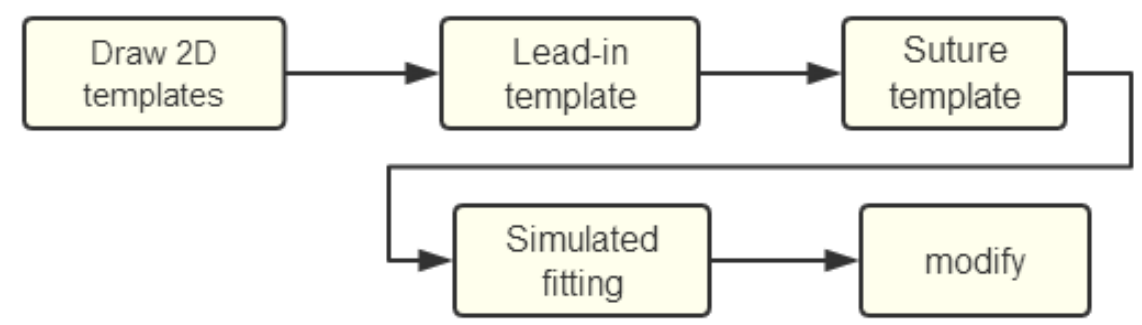

Fig. 7. Fitting steps based on CLO3D 


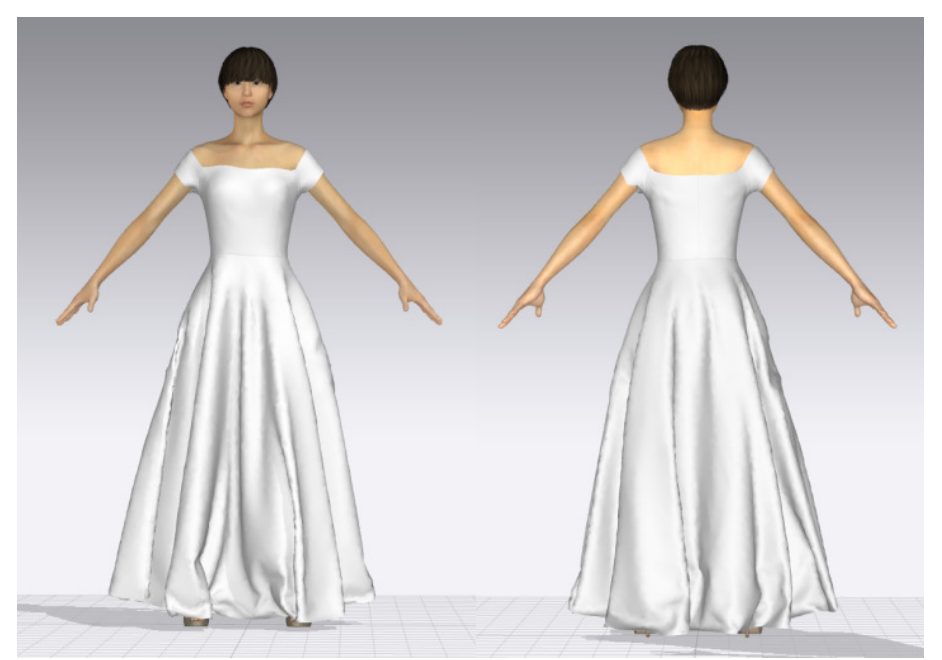

Fig.8. The effect of CLO 3D virtual fitting

\subsubsection{Structure optimization}

The pressure shift in different states of performers is analyzed in real time, the optimal pressure of the 3 bunches dress in the main part of the value: $2.10 \mathrm{kPa}-3.10 \mathrm{kPa}$. And the degree of comfort clothing in CLO 3D is presented by the pressure distribution and contact point distribution is presented. In CLO 3D, the degree of force of the garment is indicated by color: the red area get greater, the ensile strength of the fabric become larger, and the pressure become bigger; on the contrary, the green area is greater that the weakening of the garment fabric tensile strength and the pressure of clothing becomes weaker (fig.9). In addition, the amount of looseness between the garment and the human body can be shown by adjusting the transparency of the garment (fig.10). Combined with the test and software analysis, the dress and the human body were adjusted continuously, not only optimize the structure of dress, but also reached the fit of clothing and human body.

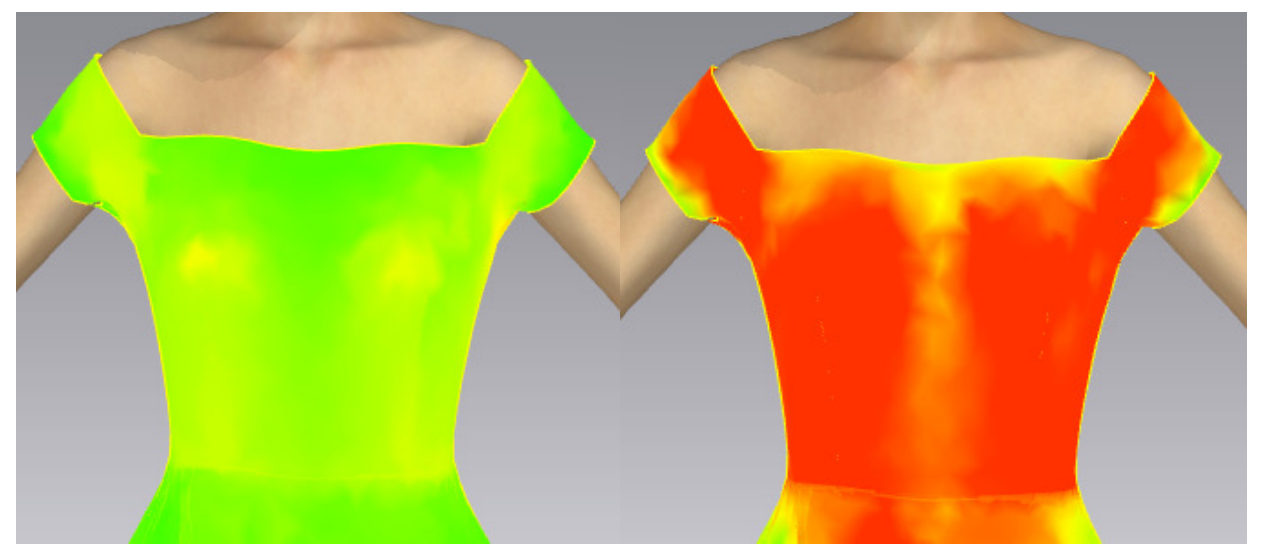

Fig.9. Pressure distribution.

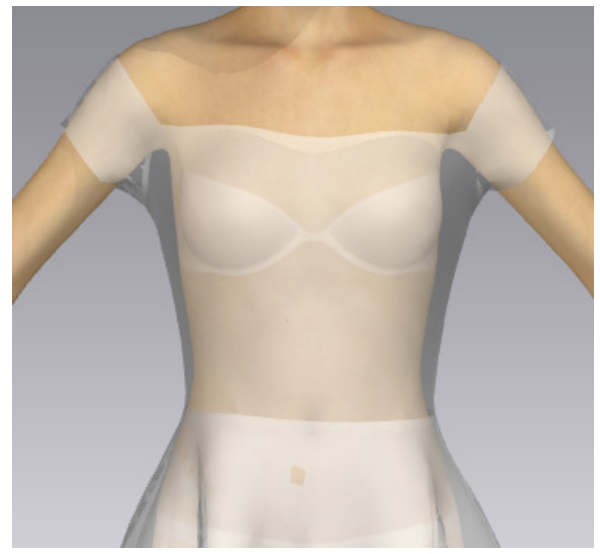

Fig .10. Loose situation 


\subsection{Impact assessment}

This paper combines the clothing pressure test with the 3D human body scanning technique and the virtual garment fitting technique. Providing that the body ergonomic condition, the clothing pressure values of the chest height, chest circumference and abdomen should be measured and human body data should be measured by 3D scanning technique. After the measurement is done, the whole body data will be imported to Clo3D. Then put the measurement of pressure value and human data combined with virtual fitting to optimize the dress and recoil As we can tell, the optimized dress, not only does not affect its beauty, but also more in line with the singer's movement, so that performers can freely move and breathe on the stage and to achieve high quality stage effects.

\section{References}

1. Liu Dawei, Huang Changhong. Theory, teaching and training of vocal music course[M]. Nanjing ,Nanjing Normal University press, 2008,pp.32

2. Zhang Wenbin, Fang Fang, ergonomics of clothing, Shanghai[M]., Donghua University press, 2008, pp.182-196

3. Jiang Huai, Lin Lantian, Sun Xiong "common / special clothing function composition, evaluation and Prospect of (on)", Shanghai [M]. Donghua University press, 2006,pp.32 